\title{
On the Effect of Hot-Water Pretreatment in Sulfur-Free Pulping of Aspen and Wheat Straw
}

\section{Hyväkkö, Uula}

2020-01-14

Hyväkkö , U , Maltari , R , Kakko, T, Kontro , J , Mikkilä , J , Kilpeläinen , P , Enqvist , E , Tikka , P , Hilden , K , Nousiainen , P \& Sipilä , J 2020 , ' On the Effect of Hot-Water

Pretreatment in Sulfur-Free Pulping of Aspen and Wheat Straw ' , ACS Omega, vol. 5 , no.

1 , pp. 265-273 . https://doi.org/10.1021/acsomega.9b02619

http://hdl.handle.net/10138/309552

https://doi.org/10.1021/acsomega.9b02619

other

publishedVersion

Downloaded from Helda, University of Helsinki institutional repository.

This is an electronic reprint of the original article.

This reprint may differ from the original in pagination and typographic detail.

Please cite the original version. 


\title{
On the Effect of Hot-Water Pretreatment in Sulfur-Free Pulping of Aspen and Wheat Straw
}

\author{
Uula Hyväkkö, ${ }^{\dagger, \perp}$ Riku Maltari, ${ }^{\dagger, \dagger, \perp}$ Tia Kakko, ${ }^{\dagger}$ Jussi Kontro, ${ }^{\dagger}$ Joona Mikkilä, ${ }^{\dagger \dagger}$ Petri Kilpeläinen, ${ }^{\S}$

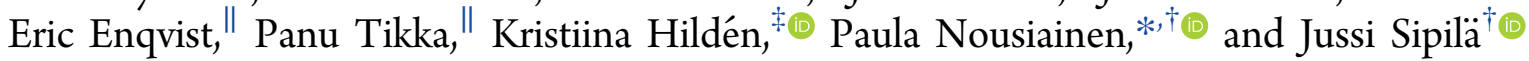 \\ ${ }^{\dagger}$ Department of Chemistry, University of Helsinki, P.O. Box 55, A.I. Virtasen Aukio 1, Helsinki FI-00014, Finland \\ ${ }^{\ddagger}$ Department of Microbiology, University of Helsinki, P.O. Box 56, Viikinkaari 9, Helsinki FI-00014, Finland \\ ${ }^{\S}$ Natural Resources Institute Finland, Tietotie 2, Espoo FI-02150, Finland \\ "SciTech-Service Oy, Ltd, Eteläesplanadi 22, Helsinki FI-00130, Finland
}

Supporting Information

\begin{abstract}
In modern biorefineries, low value lignin and hemicellulose fractions are produced as side streams. New extraction methods for their purification are needed in order to utilize the whole biomass more efficiently and to produce special target products. In several new applications using plant-based biomaterials, the native-type chemical and polymeric properties are desired. Especially, production of high-quality native-type lignin enables valorization of biomass entirely, thus making novel processes sustainable and economically viable. To investigate sulfur-free possibilities for so-called "lignin first" technologies, we compared alkaline organosolv, formic acid organosolv, and ionic liquid processes to simple soda "cooking" using wheat straw and aspen as raw

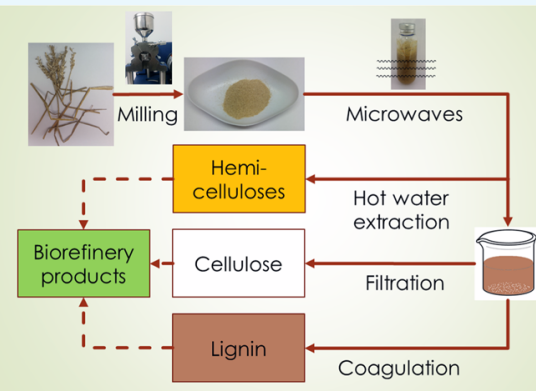
materials. All experiments were carried out using microwave-assisted pulping approach to enable rapid heat transfer and convenient control of temperature and pressure. The main target was to evaluate the advantage of a brief hot water extraction as a pretreatment for the pulping process. Most of these novel pulping methods resulted in high-quality lignin, which may be valorized more diversely than kraft lignin. Lignin fractions were thoroughly analyzed with NMR $\left({ }^{13} \mathrm{C}\right.$ and $\left.\mathrm{HSQC}\right)$ and gel permeation chromatography to study the quality of the collected lignin. The cellulose fractions were analyzed by determining their lignin contents and carbohydrate profiles for further utilization in cellulose-based products or biofuels.
\end{abstract}

\section{INTRODUCTION}

The rapid increase in the demand for materials and energy has made it necessary to find new sustainable sources of fine chemicals and liquid fuels. ${ }^{1,2}$ Exhaustion of fossil fuels and growing concern about greenhouse emissions drive the interest into lignocellulosic biomass. As the most abundant source of concentrated organic material, it can be processed into renewable materials, such as textile fibers and platform chemicals for industrial processes. ${ }^{3,4}$ Lignocellulosic biomass is a renewable carbon-neutral resource, which makes it an lucrative option for various product streams. Carbohydrates can be converted, for example, to biofuels, such as ethanol and butanol, via saccharification and fermentation. ${ }^{5}$ Lignin side streams have potential to replace fossil-based aromatics in production of phenolic substructures and larger phenolic materials, for example, aromatic chemicals, antioxidants, phenolic resins, adhesives, binders, carbon fiber precursors, biofuels, and fuel additives. ${ }^{6-8}$ Hemicelluloses have potential, for example, as hydrophilic swelling agents in pharmaceutical, biomedical, and food industries. Other applications include gels and biofilms in textile and paper industries as well as in aerogels for thermal insulation materials. ${ }^{9,22}$
For valorization of biomass, it is necessary to break down the recalcitrant cell wall structures that protect the plant from environmental decay and assures resistance to both chemical and biological attacks. ${ }^{10}$ Currently, in pulp mills, the kraft process is the most dominant pulping method for breaking down the wood cell wall structures, enabling effective valorization of the plant carbohydrates with concomitant formation of kraft lignin. This extremely complex industrial process has required more than hundred years of technological and methodological development. ${ }^{11}$ Even though it is economically viable way to separate cellulose fibers, it requires huge initial investments, and in the process itself around half of the initial material, that is, lignin and hemicellulose, ends up in the cooking liquor as nonvalue side stream. Kraft lignin is mostly combusted for heat energy because worthwhile applications have been lacking because of its heterogeneous nature. Thus, novel, straightforward, technologically less demanding, and sulfur-free processing methods are needed for pulping of wood (e.g., aspen) and agricultural crop waste

Received: August 14, 2019

Accepted: November 13, 2019

Published: December 23, 2019 
Table 1. Yields and Weight Average Degrees of Polymerization of Cellulose-Rich Fractions (C) Obtained in Various Wheat Straw Cooking Experiments (1-9)

\begin{tabular}{|c|c|c|c|c|c|c|c|c|c|}
\hline \multirow[b]{2}{*}{ \# } & \multirow[b]{2}{*}{ "cooking" liquors } & \multirow[b]{2}{*}{$T\left({ }^{\circ} \mathrm{C}\right)$} & \multirow[b]{2}{*}{ time $(\mathrm{h})$} & \multirow[b]{2}{*}{ yield of C (wt \%) } & \multirow[b]{2}{*}{ cellulose $\mathrm{DP}_{\mathrm{w}}{ }^{b}$} & \multicolumn{4}{|c|}{ wt $\%$ in fraction $\mathrm{C}$} \\
\hline & & & & & & hemicelluloses & lignin & ash & cellulose $^{c}$ \\
\hline 1 & $\mathrm{HCOOH}$ & 101 & 0.5 & 50 & 3500 & 9 & 4 & 14 & 73 \\
\hline 2 & $\mathrm{HWE}^{a}+\mathrm{HCOOH}$ & 101 & 0.5 & 44 & 3100 & 7 & 5 & 9 & 79 \\
\hline 3 & {$[\mathrm{TEAH}]\left[\mathrm{HSO}_{4}\right]$} & 120 & 4 & 41 & 1800 & 10 & 5 & 15 & 70 \\
\hline 4 & $\mathrm{HWE}^{a}+[\mathrm{TEAH}]\left[\mathrm{HSO}_{4}\right]$ & 120 & 4 & 39 & 800 & 8 & 7 & 12 & 73 \\
\hline 5 & $\mathrm{EtOH} / \mathrm{Na}_{2} \mathrm{CO}_{3}$ & 130 & 2 & 66 & 5300 & 30 & 8 & 10 & 52 \\
\hline 6 & $\mathrm{HWE}^{a}+\mathrm{EtOH} / \mathrm{Na}_{2} \mathrm{CO}_{3}$ & 130 & 2 & 49 & 4200 & 15 & 8 & 9 & 68 \\
\hline 7 & $\mathrm{EtOH} / \mathrm{NaOH}$ & 130 & 2 & 66 & 5300 & 33 & 6 & 10 & 51 \\
\hline 8 & $0.1 \mathrm{M} \mathrm{HCl}+0.1 \mathrm{M} \mathrm{NaOH}$ & 100 & $2+2$ & 45 & 3300 & 14 & 16 & 0.5 & 70 \\
\hline 9 & $1 \mathrm{M} \mathrm{NaOH}$ & 130 & 2 & 39 & 4300 & 17 & 2 & 3 & 78 \\
\hline
\end{tabular}

${ }^{a} \mathrm{HWE}\left(5 \mathrm{~min}\right.$ at $\left.185{ }^{\circ} \mathrm{C}\right) \cdot{ }^{b} \mathrm{DP}_{\mathrm{w}}=M_{\mathrm{w}} / \mathrm{AGU}$ (anhydro glucose unit $=162 \mathrm{~g} \mathrm{~mol}^{-1}$ ). ${ }^{c}$ Cellulose calculated as $100 \%-($ hemicelluloses + lignin + ash)\%.

(e.g., wheat straw). In addition, the goal is to collect lignin and hemicellulose as separate fractions, while reducing the costs and complexity of the chemical recycling and still providing comparable pulping results. ${ }^{12}$

Traditional sulfur-free pulping methods, such as the soda $(\mathrm{NaOH})$ process, are very efficient in processing of annual plants such as wheat straw. Sodium carbonate $\left(\mathrm{Na}_{2} \mathrm{CO}_{3}\right)$ has also been used as an alkali to obtain comparable results when used in conjunction with aqueous ethanol-based alkaline organosolv process. One example of such a process involves impregnation of wheat straw in concentrated solution of $\mathrm{Na}_{2} \mathrm{CO}_{3}$ followed by treatment with hot gaseous ethanol, yielding a cellulose-rich material with a low lignin content. ${ }^{13}$ Formic acid is another interesting organosolv-type solvent that has been used to delignify bamboo biomass efficiently in microwave-assisted extraction. However, without irradiation, the delignification was incomplete. ${ }^{14}$ Formic acid has also been shown to promote the cleavage of $\beta$-O-4-structure of oxidized lignin. The resulting simple aromatic compounds could provide a stream of renewable aromatic platform chemicals, solvents, and other useful aromatic compounds. ${ }^{15}$

Recently, ionic liquids (ILs) have gained lot of attention as "green" solvents for biomass deconstruction and fractionation because of their capability to dissolve biopolymers. ${ }^{16,17}$ Drawbacks with ILs include their high price and problems in recyclability because of their nonvolatile nature. Even though distillable ILs have been developed, and their prices have been significantly reduced over the years, their estimated production costs remain relatively high. ${ }^{18}$ The potential of aqueous solution of protic ILs for biomass processing has been discovered recently. ${ }^{19}$ This type of ILs (or their aqueous electrolyte solutions) can have "self-cleaning properties" and their price can be close to common laboratory solvents such as acetone or toluene. ${ }^{20}$

In order to facilitate pulping, hot water extraction (HWE) has been studied as potential pretreatment for delignification process. ${ }^{21}$ It is an intensive and quick extraction process, which has been shown to release most of the hemicelluloses in lignocellulosic biomass. ${ }^{22}$ Very recently, HWE of poplar has been shown to result in only minor changes in the lignin structure but still significantly decreases the cell wall recalcitrance. $^{23}$ The method has been scaled up using the flow-through system in the pilot scale for birch and spruce with high hemicellulose yields. ${ }^{24}$

Microwave-assisted extractions have been shown in several occasions to increase the efficiency of biomass processing. ${ }^{25}$
Enzymatic digestibility of switchgrass has been increased by utilizing microwaves instead of traditional heating. ${ }^{26}$ Microwaves generate the heat by direct interaction with the heated material, which advantageously affect process times and decrease energy inputs compared to traditional heating. ${ }^{27}$

In this paper, we studied processing of wheat straw and aspen by adopting various recently published methods including HWE pretreatment and comparing those with traditional $\mathrm{NaOH}$ treatment utilizing a microwave reactor for all procedures. Cellulose- and lignin-containing fractions were isolated and analyzed by compositional analysis (e.g., acetylbromide method and methanolysis), molecular weight distribution (MWD) analysis, and structural analysis by NMR. We show that HWE enhances fractionation of wheat straw and aspen into practically unaltered lignin together with high molecular weight cellulose, which can be further refined.

\section{RESULTS AND DISCUSSION}

The objective of the different treatments was to produce materials that can be efficiently valorized in order to utilize all the biomass constituents in integrated biorefineries. After each treatment, isolated hemicellulose fractions (A), cellulose fractions (C), and lignin fractions (D) were separately analyzed using similar procedures to be able to directly compare different treatment conditions (Figure 2). The yield and the composition of the isolated fractions were determined to assess the performance of the process. Structural characterization of resulting materials can be used to evaluate their potential for further applications.

Wheat Straw Hemicellulose Fraction (A). Hemicellulose content of original extractive-free wheat straw was determined to be approx. $31 \%(\mathrm{w} / \mathrm{w})$ by acid methanolysis. HWEs for wheat straw gave an average yield of $16 \mathrm{wt} \%(\mathrm{w} / \mathrm{w})$ for hemicellulose fraction (A), which corresponds $53 \%$ of total hemicellulose content in untreated wheat straw. The hemicellulose content in wheat straw mostly consisted of xylose, arabinose, 4-O-Me-glucuronic acid and galacturonic acid, and rhamnose originated from pectin (Table S4.1). HSQC-NMR spectra of fraction (A) indicated a significant hemicellulose content with small amounts of lignin (Figure S8.1), which was evaluated to be $12 \%$ by $\mathrm{Py}-\mathrm{GC}-\mathrm{MS}$.

Previously, HWE has been shown to increase the porosity of the cell walls, ${ }^{28}$ enhancing accessibility of cooking chemicals and effectivity of hydrolyzing enzymes in bioethanol production. HWE induces autocatalytic reactions where hemicellulose acetyl groups are partially released, resulting in 
Table 2. Yield and Structural Quality of Collected Acetylated Lignin Fraction (D) from Wheat Straw

\begin{tabular}{|c|c|c|c|c|c|c|c|c|c|}
\hline \# & “cooking” liquors & $T\left({ }^{\circ} \mathrm{C}\right)$ & $\underset{(\mathrm{h})}{\operatorname{time}}$ & $\begin{array}{c}\text { lignin rich yield } \\
(\text { wt \%) }\end{array}$ & $\begin{array}{c}\beta \text {-O-4 signals } \\
\text { (HSQC) }\end{array}$ & $M_{\mathrm{w}}$ & $M_{\mathrm{n}}$ & $\begin{array}{c}\text { PDI } \\
\left(M_{\mathrm{w}} / M_{\mathrm{n}}\right)\end{array}$ & $\begin{array}{c}\text { carbohydrate signal } \\
\text { (HSQC) }\end{array}$ \\
\hline 1 & $\mathrm{HCOOH}$ & 101 & 0.5 & 13 & strong & 4270 & 1900 & 2.25 & weak \\
\hline 2 & $\mathrm{HWE}^{a}+\mathrm{HCOOH}$ & 101 & 0.5 & 8 & strong & 3640 & 1710 & 2.12 & weak \\
\hline 3 & {$[\mathrm{TEAH}]\left[\mathrm{HSO}_{4}\right]$} & 120 & 4 & 12 & n.s. & 2530 & 1310 & 1.94 & n.s. \\
\hline 4 & $\mathrm{HWE}^{a}+[\mathrm{TEAH}]\left[\mathrm{HSO}_{4}\right]$ & 120 & 4 & 8 & n.s. & 2270 & 1220 & 1.86 & n.s. \\
\hline 5 & $\mathrm{EtOH} / \mathrm{Na}_{2} \mathrm{CO}_{3}$ & 130 & 2 & 8 & strong & 3030 & 1300 & 2.33 & strong \\
\hline 6 & $\mathrm{HWE}^{a}+\mathrm{EtOH} / \mathrm{Na}_{2} \mathrm{CO}_{3}$ & 130 & 2 & 13 & strong & 3120 & 1380 & 2.27 & weak \\
\hline 7 & $\mathrm{EtOH} / \mathrm{NaOH}$ & 130 & 2 & 14 & strong & 3180 & 1330 & 2.39 & strong \\
\hline 8 & $0.1 \mathrm{M} \mathrm{HCl}+0.1 \mathrm{M} \mathrm{NaOH}$ & 100 & $2+2$ & 11 & strong & 3700 & 1390 & 2.66 & strong \\
\hline 9 & $1 \mathrm{M} \mathrm{NaOH}$ & 130 & 2 & 24 & strong & 2980 & 1210 & 2.45 & strong \\
\hline
\end{tabular}

${ }^{a} \mathrm{HWE}\left(5 \mathrm{~min}\right.$ at $\left.185^{\circ} \mathrm{C}\right)$. No signal is specified as n.s. $M_{\mathrm{n}}=$ number-average molecular weight, $M_{\mathrm{W}}=$ weight-average molecular weight, and polydispersity $=$ PDI $\left(M_{\mathrm{w}} / M_{\mathrm{n}}\right)$.

formation of acidic conditions. ${ }^{29}$ Hemicelluloses of wheat straw and aspen consist of xylan backbone with significant amount of acetylated units. ${ }^{30}$ Based on HSQC-NMR, HWEtreated samples (A) contained acetyl signals at 2.0/20 ppm showing that acetyl groups survive in HWE conditions (Figure S8.1). According to literature, only basic conditions can release the majority of hemicellulose acetyl-groups. ${ }^{31}$ In HWE conditions, thermally labile hemicelluloses are simultaneously solubilized and degraded, depending on the reaction conditions, to yield oligo- and monomeric sugars. Mihiretu et al. showed that below $185{ }^{\circ} \mathrm{C}$, only a small amount of hemicellulose fractions were degraded to monomers, while at higher temperatures and longer reaction times, more fragmented sugars were formed. ${ }^{43}$ Gel permeation chromatography (GPC) analysis of the fraction isolated after $5 \mathrm{~min}$ extraction at $185{ }^{\circ} \mathrm{C}$ showed bimodal MWD with high polydispersity, ranging from 0.5 to $50 \mathrm{kDa}$, which corresponds to weight average degree of polymerization $\left(\mathrm{DP}_{\mathrm{W}}\right) 3-300$ (Figure S2). The average hemicellulose $\mathrm{DP}_{\mathrm{W}}$ has been reported to vary between 20 and $400,32,33$ which suggests degradation and solubilization of some fragments, and that the wheat straw hemicellulose backbone was mostly left intact.

Wheat Straw Cellulose Fraction. Results of cooking treatments for wheat straw and their impact on the yield of cellulose-rich fraction, contents of residual lignin and ash, and $\mathrm{DP}_{\mathrm{W}}$ of cellulose are presented in Table 1. Untreated extractive-free wheat straw contained $31 \%(\mathrm{w} / \mathrm{w})$ hemicelluloses, 23\% lignin, and 9\% ash.

Most of the pulping methods gave adequate cellulose yields with relatively low lignin contents. The ash contents, however, mainly consisting of silicates, remained relatively high in all acidic, IL (1-4) and mild alkaline (5-7) treatments, which may cause problems in further processing. Only alkaline extractions (8-9) with high water content seemed to efficiently remove silicates and other inorganics.

In formic acid and IL (triethylammonium hydrogen sulfate, $\left.[\mathrm{TEAH}]\left[\mathrm{HSO}_{4}\right]\right)$ treatments $(1-4)$, HWE pretreatment did not notably reduce the yields of cellulose fractions $C$, suggesting that without $\mathrm{HWE}$, most of the hemicelluloses end up in spent liquor (Table 1). This is confirmed by the fact that residual hemicellulose contents were not notably reduced in comparison with HWE-treated samples (Table 1). HWE indeed seems to be a rapid method to collect hemicelluloses as relatively pure fraction, which is also supported by literature. $^{21-24}$ As HWE was carried out at relatively high temperature $\left(185{ }^{\circ} \mathrm{C}\right)$, which can cause damage to the cellulosic polymers, the MWDs of all cellulose fractions (C) were determined by GPC.

The GPC chromatograms from cellulose fractions (Figure S1a) showed similar behavior for all cooks in conventional acidic conditions ( $\mathbf{1}$ and $\mathbf{2}$ with formic acid and $\mathbf{8}$ using mild $\mathrm{HCl}$ ). The MWDs of the carbohydrates were slightly reduced, and the amount of low molecular weight part was approximately half compared to caustic soda $(\mathrm{NaOH})$ extraction (9, Figure S1c). This is in line with their residual hemicellulose contents (Table 1). The carbohydrate compositional analysis revealed that acidic treatments removed almost all other hemicellulose sugars except xylose and glucose (Table S4.1). Glucose can originate partially from cellulose because acid methanolysis can depolymerize noncrystalline cellulose. In alkaline conditions (5-7 and 9), the chromatograms have a bimodal structure including separate lower and higher MW fractions with almost baseline separation. As expected, the lower MW contained mostly hemicelluloses. ${ }^{34}$ The largest hemicellulose contents were found in mildly alkaline organosolv treatments (5 and 7), which suggests that hemicelluloses were sparingly soluble (Table 1). In alkaline conditions, cellulose fractions (C) contained arabinose and 4-O-Meglucuronic acid (Table S4.1). In aqueous protic IL cooks (3 and 4), the MWDs had one maximum (Figure S1b), and the $\mathrm{DP}_{\mathrm{W}}$ values were 1849 and 856 , respectively. In all wheat straw experiments, HWE pretreatment lowered the hemicellulose content but also reduced $\mathrm{DP}_{\mathrm{W}}$ of cellulose. The contribution of the HWE in removal of hemicelluloses was either insignificant $(2,4)$ or large $(6)$ compared to corresponding experiments without the HWE pretreatment $(\mathbf{1}, 3,5)$. The residual hemicelluloses in fraction $\mathrm{C}$ were predominantly xylose and glucose, according to methanolysis. Sample dissolution procedure in the GPC analysis for carbohydrates is commonly used for cellulosic pulp samples. In present study, the dissolution was not complete but this likely has no major effect on $\mathrm{DP}_{\mathrm{W}}$ values.

Wheat Straw Lignin Fraction. Isolation of lignin from biomass modifies its natural structure, depending on the severity of the treatment. Structural changes together with impurities that travel with lignin affect further reactivity, for example, in depolymerization reactions. The most important structure in lignin is $\beta$-O-4-ether linkage, which typically enables chemical modification through the free benzylic hydroxyl groups in lignin backbone (e.g., esterification, etherification, crosslinking, copolymerization, and oxidation) later in the biorefinery process stream. ${ }^{6}$ Structural characteristics and lignin quality were assessed by HSQC-NMR. Full 
5. WS $6: 4 \mathrm{EtOH}: 0.25 \mathrm{M} \mathrm{Na}_{2} \mathrm{CO}_{3}$

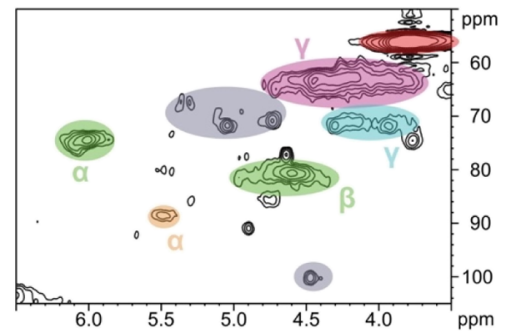

10. Aspen $88 \% \mathrm{HCOOH}$

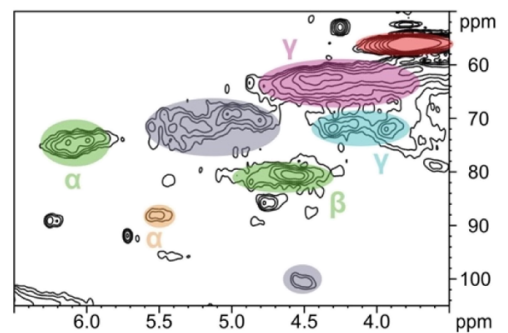

14. Aspen 6:4 EtOH : $0.25 \mathrm{M} \mathrm{Na}_{2} \mathrm{CO}_{3}$
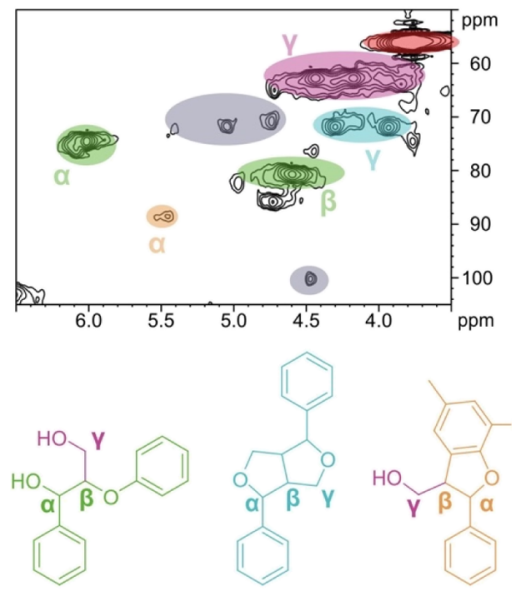

$\beta-\beta$

6. WS HWE + 6:4 EtOH : $0.25 \mathrm{M} \mathrm{Na}_{2} \mathrm{CO}_{3}$

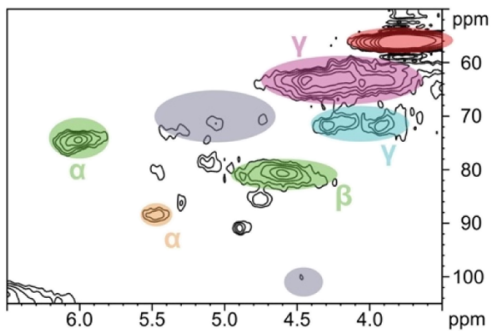

11. Aspen $\mathrm{HWE}+88 \% \mathrm{HCOOH}$

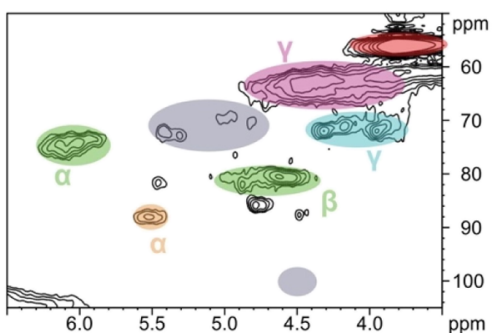

15. Aspen HWE + 6:4 EtOH : $0.25 \mathrm{M} \mathrm{Na}_{2} \mathrm{CO}_{3}$

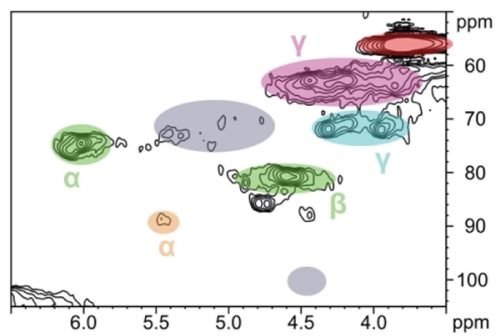

$-\mathrm{O}-\mathrm{CH}_{3}$

Methoxyl

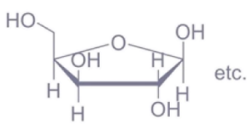

Carbohydrates

Figure 1. Changes in the lignin phenylpropyl side-chain region with and without HWE treated in mild organosolv conditions (5-6, wheat straw) and (14-15, aspen), and in formic acid conditions (10-11 aspen). Carbohydrate signals were weakened with HWE pretreatment.

area spectra of all samples and selected ${ }^{13} \mathrm{C}$ NMR spectra are presented in Figures S3 and S4. The signals of $\beta$-O-4-ether linkage in HSQC are found at 6.1/74.2 and 4.6/80.5 ppm for phenylpropanoid side-chain $\mathrm{C} \alpha$ and $\mathrm{C} \beta$ positions, respectively. ${ }^{35}$ Carbohydrates were identified by the anomeric carbon signal at 4.5/100.3 ppm. Yields, molecular weight averages, and qualitative analysis of lignin fractions (D) are in Table 2.

Formic acid treatment was found to derivatize lignin chemically shown by the presence of formate ester signals at $8.1 / 160 \mathrm{ppm}$ in the HSQC NMR spectra. The labile formate groups improve lignin solubility, which can be advantageous for processing. The IL procedures (3-4) yielded highly soluble lignin with the nonexistent $\beta$-O-4-ether structure. Treatment with $\mathrm{NaOH}(9)$ produced poorly soluble lignin in acetylation. The HSQC of the soluble part contained strong signals for $\beta$-O- 4 and carbohydrates, suggesting the presence of lignin-carbohydrate complexes (LCCs). ${ }^{36,37}$

Interestingly, HWE pretreatment decreased the lignin yield (Table 2) in all treatments except in mild alkaline organosolv conditions (6). The increased lignin yield was accompanied by reduction in hemicellulose signals in HSQC (Figure 1). This suggests that by removing the hemicelluloses by HWE pretreatment, alkali is able to permeate the cell wall more easily and enhance lignin dissolution. According to HSQC, the lignin $\beta$-O-4-signals in wheat straw fractions (D) remained strong except in IL treatments. Carbohydrates were mostly absent in all HWE-pretreated samples (2, 4, and 6, Table 2).

The average molecular weight of each lignin fraction (D) was analyzed by GPC (Figure S5). The HWE pretreatment reduced $M_{\mathrm{w}}$ by $15 \%$ when combined with acidic cooking in formic acid (1-2) and by $10 \%$ in IL (3-4). The IL treatment provided the narrowest distribution indicating most uniform product. The mild acid treatment followed by mild alkali (8) showed similar $M_{\mathrm{w}}$-value compared to HWE and formic acid treated sample (2). In mild alkaline organosolv conditions, HWE did not affect molecular mass distribution of lignin fractions (D) (5-6). The MWDs in general were very similar with all alkaline treatments by $\mathrm{NaOH}$ and $\mathrm{Na}_{2} \mathrm{CO}_{3}(5-7)$. The soda-treated lignin (9) had slightly lower MW than the alkaline organosolv-cooked samples. 


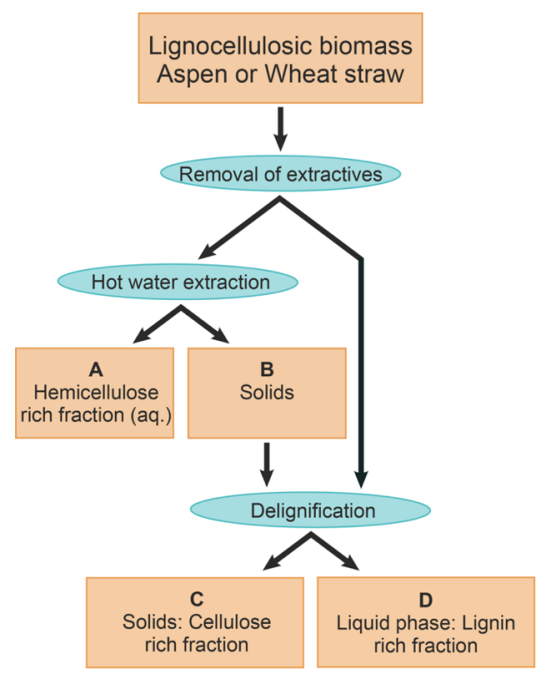

Figure 2. Scheme on fractionation procedures on the biomass.

Because delignification of wheat straw was almost complete with nearly all cooking procedures, in order to produce an effective process, the main parameters to consider are cellulose fraction yield and lignin fraction purity. With that in mind, the mild organosolv with $\mathrm{Na}_{2} \mathrm{CO}_{3}$ combined with $\mathrm{HWE}$ pretreatment is the superior process, where both yield and purity of the lignin fraction increased without affecting the MWD.

Aspen Hemicellulose Fraction (A). Approximate the hemicellulose content of extractive-free aspen was determined to be $31 \%(\mathrm{w} / \mathrm{w})$. HWE for aspen gave hemicellulose fraction in an average yield of $25 \mathrm{wt} \%(\mathrm{w} / \mathrm{w})$, corresponding to $82 \%$ of total hemicelluloses. HWE treatment produced hemicellulose fraction with only $5 \%$ lignin evaluated by $\mathrm{Py}-\mathrm{GC}-\mathrm{MS}$ and HSQC-NMR. According to GPC results of hemicellulose fractions, aspen HWE extraction gave structurally more uniform product without the higher MW part present in wheat straw hemicellulose fraction. The observed hemicellulose $\mathrm{MW}$ range was $0.5-8 \mathrm{kDa}\left(\mathrm{DP}_{\mathrm{W}} 3-50\right)$ with notably smaller $M_{\mathrm{w}}$ of $1.5 \mathrm{kDa}$ compared to wheat straw $(8 \mathrm{kDa})$ (Table S3). The smaller $M_{\mathrm{w}}$, lack of lignin fragments in the PyGC-MS and HSQC-signals (Figure S8.2), suggests that aspen cell wall morphology allows easier separation of its components than wheat straw.

Aspen Cellulose Fraction. Hemicellulose and lignin contents for aspen cellulose fraction are in Table 3. Ash contents were not measured, as there are insignificant amounts of inorganics in aspen. Extractive-free aspen was determined to contain 31\% (w/w) hemicelluloses and 19\% lignin.

Aspen, a woody biomass, was more resistant to chemical deconstruction than wheat straw. Formic acid and IL procedures (10-13, Table 3) yielded cellulose fractions (C) with low lignin contents while alkaline extractions (14-18, Table 3) resulted in low delignification. Furthermore, in alkaline conditions, the isolated cellulose fractions contained small amounts of arabinose, rhamnose, and uronic acids (Table S4.2). HWE before organosolv treatment (15) removed most of other sugars except xylose and glucose. The cellulose fractions after treatments $\mathbf{1 7}$ and $\mathbf{1 8}$ (Table 3) had the highest lignin content, which suggests removal of mostly hemicelluloses during the procedure.

HWE pretreatment lowered slightly cellulose fraction (C) yield in formic acid procedure (10-11), which indicates that without HWE, most of the hemicelluloses dissolved in the cooking liquor similar to wheat straw treatments. In the case of the IL solutions (12 and 13, Table 3), the yields were around $35 \%$, but the overall cellulose yield and $\mathrm{DP}_{\mathrm{W}}$ were low compared to other treatments. HWE seemed to improve pulping in mild organosolv (15), however, the lignin content in fraction $\mathrm{C}$ remained relatively high (Table 3 ).

MWDs in aspen cellulose fractions (C) were determined by GPC. HWE reduced substantially the $\mathrm{DP}_{\mathrm{W}}$ of aspen cellulose (Table 3, Figure S1d-f). This was in line with previous study, which showed reduction of the cell wall recalcitrance of poplar by reducing the cellulose DP when hydrothermal treatment was performed. ${ }^{23}$ Treatments in acidic conditions (10,11 and 17) produced reduced DPs with large PDIs (Figure S1d-f). In alkaline treatments without $\operatorname{HWE}(\mathbf{1 4}, 16$, and 18), chromatograms showed a bimodal shape, which is indication of both hemicelluloses and cellulose in the sample. HWE pretreatment with organosolv (15) removed the low MW fraction with concomitant induction of cellulose hydrolysis. Overall, the largest $\mathrm{DP}_{\mathrm{W}}$ for cellulose (Table S2) was obtained with the alkaline cooks. The IL treatments had the smallest $\mathrm{DP}_{\mathrm{W}}(12-$ 13), approximately one-third of the highest $\mathrm{DP}_{\mathrm{W}}$ value $(\mathbf{1 8})$ in soda-cooking conditions. This suggests that cellulose was degraded during the treatments presumably because the solution was strongly acidic. This was the case in most of the acidic treatments $(\mathbf{1 1}, \mathbf{1 7}$, Table 3$)$. It is noteworthy that the IL treatment produced relatively clean cellulose fractions. The cellulose produced this way may be used in enzymatic bioethanol production because reduced $\mathrm{DP}_{\mathrm{W}}$ allows for more efficient reactions with cellulases. ${ }^{38}$

Table 3. Results of the Cellulose Fraction (C) of Aspen Sawdust Treatments (10-18) in Various Solvent Systems

\begin{tabular}{|c|c|c|c|c|c|c|c|c|}
\hline \multirow[b]{2}{*}{$\#$} & \multirow[b]{2}{*}{ solvent system } & \multirow[b]{2}{*}{$T\left({ }^{\circ} \mathrm{C}\right)$} & \multirow[b]{2}{*}{ time $(\mathrm{h})$} & \multirow[b]{2}{*}{ yield of C (wt \%) } & \multirow[b]{2}{*}{ cellulose $\mathrm{DP}_{\mathrm{w}}{ }^{b}$} & \multicolumn{3}{|c|}{ wt $\%$ in fraction $\mathrm{C}$} \\
\hline & & & & & & hemi-celluloses & lignin & cellulose $^{c}$ \\
\hline 10 & $\mathrm{HCOOH}$ & 101 & 0.5 & 54 & 2100 & 10 & 4 & 86 \\
\hline 11 & $\mathrm{HWE}^{a}+\mathrm{HCOOH}$ & 101 & 0.5 & 47 & 1200 & 7 & 4 & 89 \\
\hline 12 & {$[\mathrm{TEAH}]\left[\mathrm{HSO}_{4}\right]$} & 120 & 4 & 34 & 900 & 7 & 5 & 88 \\
\hline 13 & $\mathrm{HWE}^{a}+[\mathrm{TEAH}]\left[\mathrm{HSO}_{4}\right]$ & 120 & 4 & 36 & 500 & 5 & 6 & 89 \\
\hline 14 & $\mathrm{EtOH} / \mathrm{Na}_{2} \mathrm{CO}_{3}$ & 130 & 2 & 79 & 4100 & 22 & 17 & 61 \\
\hline 15 & $\mathrm{HWE}^{a}+\mathrm{EtOH} / \mathrm{Na}_{2} \mathrm{CO}_{3}$ & 130 & 2 & 42 & 1700 & 7 & 15 & 78 \\
\hline 16 & $\mathrm{EtOH} / \mathrm{NaOH}$ & 130 & 2 & 78 & 3900 & 22 & 17 & 61 \\
\hline 17 & $0.1 \mathrm{M} \mathrm{HCl}+0.1 \mathrm{M} \mathrm{NaOH}$ & 100 & $2+2$ & 60 & 1500 & 12 & 23 & 65 \\
\hline 18 & $1 \mathrm{M} \mathrm{NaOH}$ & 130 & 2 & 60 & 3600 & 11 & 20 & 69 \\
\hline
\end{tabular}

${ }^{a} \mathrm{HWE}\left(5 \mathrm{~min}\right.$ at $\left.185{ }^{\circ} \mathrm{C}\right) .{ }^{b} \mathrm{DP}_{\mathrm{w}}=M_{\mathrm{w}} / \mathrm{AGU}$ (anhydroglucose unit $=162 \mathrm{~g} \mathrm{~mol}^{-1}$ ). ${ }^{c}$ Cellulose calculated as $100 \%-($ hemicelluloses + lignin $) \%$. 
Table 4. Yield and Structural Quality of Collected Acetylated Lignin Rich Fraction (D) from Aspen

\begin{tabular}{|c|c|c|c|c|c|c|c|c|c|}
\hline$\#$ & solvent system & $T\left({ }^{\circ} \mathrm{C}\right)$ & $\begin{array}{l}\text { time } \\
(\mathrm{h})\end{array}$ & $\begin{array}{l}\text { lignin rich yield } \\
\text { (wt \%) }\end{array}$ & $\begin{array}{l}\beta \text {-O-4 signals } \\
\text { (HSQC) }\end{array}$ & $M_{\mathrm{w}}$ & $M_{\mathrm{n}}$ & $\begin{array}{c}\text { PDI } \\
\left(M_{\mathrm{w}} / M_{\mathrm{n}}\right)\end{array}$ & $\begin{array}{c}\text { carbohydrate signal } \\
\text { (HSQC) }\end{array}$ \\
\hline 10 & $\mathrm{HCOOH}$ & 101 & 0.5 & 12 & strong & 5100 & 1950 & 2.61 & weak \\
\hline 11 & $\mathrm{HWE}^{a}+\mathrm{HCOOH}$ & 101 & 0.5 & 8 & strong & 4080 & 1850 & 2.21 & n.s. \\
\hline 12 & {$[\mathrm{TEAH}]\left[\mathrm{HSO}_{4}\right]$} & 120 & 4 & 11 & n.s. & 3080 & 1430 & 2.15 & n.s. \\
\hline 13 & $\mathrm{HWE}^{a}+[\mathrm{TEAH}]\left[\mathrm{HSO}_{4}\right]$ & 120 & 4 & 5 & n.s. & 2230 & 1460 & 1.53 & n.s. \\
\hline 14 & $\mathrm{EtOH} / \mathrm{Na}_{2} \mathrm{CO}_{3}$ & 130 & 2 & 4 & strong & 8910 & 2110 & 4.23 & strong \\
\hline 15 & $\mathrm{HWE}^{a}+\mathrm{EtOH} / \mathrm{Na}_{2} \mathrm{CO}_{3}$ & 130 & 2 & 6 & strong & 4150 & 1480 & 2.81 & n.s. \\
\hline 16 & $\mathrm{EtOH} / \mathrm{NaOH}$ & 130 & 2 & 4 & strong & 9250 & 2240 & 4.13 & strong \\
\hline 17 & $0.1 \mathrm{M} \mathrm{HCl}+0.1 \mathrm{M} \mathrm{NaOH}$ & 100 & $2+2$ & 2 & strong & 6450 & 2060 & 3.13 & weak \\
\hline 18 & $1 \mathrm{M} \mathrm{NaOH}$ & 130 & 2 & 4 & strong & 3290 & 1460 & 2.26 & strong \\
\hline
\end{tabular}

Table 5. Experiments for Aspen Using Higher Alkalinities in Pulping Liquors ${ }^{a}$

\begin{tabular}{|c|c|c|c|c|c|c|c|c|}
\hline$\#$ & solvent system & $\begin{array}{l}\text { yield of C } \\
\text { (wt \%) }\end{array}$ & hemi-celluloses & lignin & cellulose $^{b}$ & $\begin{array}{l}\text { yield of D } \\
\text { (wt \%) }\end{array}$ & $\begin{array}{c}\beta \text {-O-4 signals } \\
\text { (HSQC) }\end{array}$ & $\begin{array}{c}\text { carbohydrate signal } \\
\text { (HSQC) }\end{array}$ \\
\hline \multicolumn{7}{|c|}{ wt \% of cellulose in fraction C } & \multicolumn{2}{|c|}{ composition of fraction $\mathrm{D}$} \\
\hline 19 & $\mathrm{EtOH} / 1 \mathrm{M} \mathrm{NaOH}$ & 82 & 21 & 13 & 66 & 7 & strong & n.s. \\
\hline 20 & $\mathrm{HWE}+\mathrm{EtOH} / 1 \mathrm{M} \mathrm{NaOH}$ & 52 & 10 & 14 & 76 & 8 & strong & n.s. \\
\hline 21 & $\mathrm{HWE}+1 \mathrm{M} \mathrm{NaOH}$ & 48 & 9 & 17 & 74 & 2 & strong & strong \\
\hline 22 & $\begin{array}{l}\mathrm{HWE}+\mathrm{EtOH} / 0.25 \mathrm{M} \\
\mathrm{NaOH}\end{array}$ & 57 & n.d. & n.d. & n.d. & 6 & n.d. & n.d. \\
\hline
\end{tabular}

Aspen Lignin Fraction. Aspen lignin fractions were collected following the same procedure that was used for wheat straw. Yields, molecular weight averages, and qualitative analysis of the lignin fractions are in Table 4.

NMR results (Figures S6 and S7) were very similar between the two starting materials with the exception of carbohydrates, and the amount of which was lower in aspen lignin fractions (D). The IL treatment (12 and 13) caused the $\beta$-O-4-structure signals to disappear, while other procedures left the structure practically intact (Figure S6). The side-chain structures were hydrolyzed because of the highly acidic conditions in the protic IL. Soda treatment (18) yielded lignin fraction with low solubility, which most likely indicates the presence of hemicelluloses similar to wheat straw experiment (9).

Pretreatment with HWE lowered $M_{\mathrm{w}}$ of aspen lignin in case of formic acid by $20 \%$ (10 and 11) or IL treatments by $28 \%$ (12 and 13) as shown by GPC analysis (Table 5). All these chromatograms showed a single maximum, and distributions were narrower with HWE-treated samples. The IL-treated samples (12 and 13) had lower average molecular sizes and PDI than formic acid-treated samples (10 and 11) indicating lignin degradation in highly acidic conditions. With mild organosolv conditions (14 and 16), the curve was bimodal but 16 contained fewer low-MW and more high-MW components pointing to the presence of LCCs. Interestingly, in carbonate organosolv with HWE (15), the MWD had one clear maximum with larger molecular mass component removed suggesting removal of hemicelluloses.

The results clearly demonstrate that with aspen, formic acid cooks produced the highest degree of delignification (Table 3), even though after the treatment lignin was not completely recovered by water precipitation. The HWE improved yields of dissolved lignins in alkaline organosolv conditions with both biomasses, but no improvement was observed with soda cook. The results also suggest that alkaline cooking is not able to create pores in the cell wall without HWE pretreatment to assist penetration of solvents and reagents into the cell wall
(Tables 4 and 5). This is in good agreement with the results obtained by Duarte et al. 2011, who demonstrated similar effect of HWE pretreatment on hardwood kraft pulp fibers. ${ }^{28}$ To confirm the role of HWE for alkaline cooking, additional experiments were made (Table 5) to study the effect of higher alkali concentration $(1 \mathrm{M})$ in the yield and constitution of lignin fraction (D). These experiments confirmed that the lignin yields increased when alkaline organosolv cook was combined with HWE.

More purified lignin fraction is preferred for further processing because carbohydrate impurities likely cause problems, for example, in modification reactions by hindering solubility ${ }^{6,39}$ The most complete separation of the biomass to the cellulose, hemicellulose, and lignin was accomplished with the combination of formic acid and HWE both for aspen and wheat straw.

\section{CONCLUSIONS}

In this study, the effect of HWE was examined as a pretreatment method when several potential pulping procedures for modern biorefineries were compared to traditional soda cooking, using wheat straw and aspen as starting biomaterials. For practical reasons, experiments were performed applying microwaves as the heat source. Especially, HWE was applied to examine the separation of carbohydrates and lignin in the cooks.

For both biomasses, HWE pretreatment produced relatively pure and uniform hemicellulose fraction that can be further used, for example, for chemicals and advanced material development. While this hemicellulose fraction in wheat straw had noticeable lignin component, aspen hemicellulose fraction barely contained detectable amounts of lignin. Hemicellulose fractions also had some unusual properties, such as small molecular weight and tendency to dissolve in organic solvents, for example, acetone. This facilitates modification of hemicellulosic materials and enables their application as value-added components in food additives and 
pharmaceutical products because they have been produced without toxic or harmful chemicals.

The HWE pretreatment also had a positive effect on further separation of lignin and cellulose in active cooks. It improved yields and purity of lignin fractions in alkaline ethanol organosolv cook with both biomasses. Interestingly, when HWE was applied to carbonate organosolv cook, considered as environmentally cost-efficient and sustainable method, reasonable delignification was obtained in wheat straw. On the other hand, in combination with formic acid cook, HWE pretreatment facilitated production of clean lignin fraction with almost completely delignified cellulose fraction. In fact, the formic acid treatments enable impressive delignification results for both biomasses regardless of the HWE pretreatment. Our findings demonstrate that a separate HWE is especially efficient in alkaline organosolv cooks.

The enhanced efficiency of separating the wood components by HWE allows the separation of the biomass into all main components of the plant cell wall (hemicellulose, cellulose, and lignin) with minimal effects on their structural composition. Most of the pulping methods examined retained the lignin native structure, which is promising for lignin utilization in further chemical processing. This potentially creates new business opportunities for biorefineries using agricultural wastes such as wheat straw. The research is particularly topical, considering the recent efforts to support circular bioeconomy and bio-based innovations.

\section{EXPERIMENTAL SECTION}

Biomass Feedstock. Wheat straw was received from southern Finland as $10-30 \mathrm{~cm}$ long stems. Remaining chaffs were removed by hand, and the stems were fed to Wiley minimill (Thomas Scientific) to pass 60 mesh. Extractives were removed from wheat straw with $\mathrm{EtOH}$ and $\mathrm{CHCl}_{3}: \mathrm{MeOH}$ at room temperature (detailed procedure in S1.1).

The naturally grown aspen was 23-24 year-old wood with 7 $\mathrm{cm}$ diameter at breast height from southern Finland. The Aspen was collected as wood and subsequently processed to sawdust to simulate logging residues. Aspen sawdust was first sterilized by briefly immersing at $90{ }^{\circ} \mathrm{C}$ in distilled water and washed with acetone and finally dried in oven at $50{ }^{\circ} \mathrm{C}$. The sterilized sawdust was then fed to Wiley mill to pass 60 mesh. Extractives were removed with acetone overnight (detailed procedure in S1.1).

Biomass Treatments. Selected treatment processes were adopted into a microwave-assisted procedure using Biotage Initiator 2.0 and Anton Parr Monowave 450 microwave reactors in reported optimized conditions. A silicon carbide reaction vessel was used in higher alkalinities. The general scheme is presented in Figure 2.

In HWE, $1.0 \mathrm{~g}$ of wheat straw or aspen powder was extracted with distilled water $\left(5 \mathrm{~min}\right.$ at $\left.185^{\circ} \mathrm{C}\right)$. Solids were filtrated and washed with distilled water, dried, and subjected to a selected delignification procedure, according to Table 6. The aqueous solution was collected and evaporated to yield hemicellulose fraction $\mathrm{A}$.

Aqueous formic acid, ${ }^{40}$ dilute $\mathrm{HCl}$ followed by dilute $\mathrm{NaOH},{ }^{41}$ aqueous IL triethylammonium hydrogen sulfate $\left([\mathrm{TEAH}]\left[\mathrm{HSO}_{4}\right]\right),{ }^{20}$ alkaline organosolv, ${ }^{42}$ and $\mathrm{HWE}^{43}$ procedures were compared to a traditional $\mathrm{NaOH}$ extraction using the same instrument. Experiments 1-9 were performed on wheat straw and experiments 10-22 with aspen.
Table 6. Constitution of Active Liquors and Reaction Conditions in the Microwave-Assisted Cooking Experiments

\begin{tabular}{lccc}
\multicolumn{1}{c}{ solvent system } & sample entry \# & $T\left({ }^{\circ} \mathrm{C}\right)$ & time (h) \\
$88 \% \mathrm{HCOOH}$ & 1,10 & 101 & 0.5 \\
$\mathrm{HWE}+88 \% \mathrm{HCOOH}$ & 2,11 & 101 & 0.5 \\
$80 \%[\mathrm{TEAH}]\left[\mathrm{HSO}_{4}\right]$ & 3,12 & 120 & 4 \\
$\mathrm{HWE}+80 \%\left[\mathrm{TEAH}^{2}\left[\mathrm{HSO}_{4}\right]\right.$ & 4,13 & 120 & 4 \\
$6: 4 \mathrm{EtOH} / 0.25 \mathrm{M} \mathrm{Na} \mathrm{CO}_{3}$ & 5,14 & 130 & 2 \\
$\mathrm{HWE}+6: 4 \mathrm{EtOH} / 0.25 \mathrm{M} \mathrm{Na} \mathrm{CO}_{3}$ & 6,15 & 130 & 2 \\
$6: 4 \mathrm{EtOH} / 0.25 \mathrm{M} \mathrm{NaOH}$ & 7,16 & 130 & 2 \\
$0.1 \mathrm{M} \mathrm{HCl}+0.1 \mathrm{M} \mathrm{NaOH}$ & 8,17 & 100 & $2+2$ \\
$1 \mathrm{M} \mathrm{NaOH}$ & 9,18 & 130 & 2 \\
$\mathrm{EtOH} / 1 \mathrm{M} \mathrm{NaOH}$ & 19 & 130 & 2 \\
$\mathrm{HWE}+\mathrm{EtOH} / 1 \mathrm{M} \mathrm{NaOH}$ & 20 & 130 & 2 \\
$\mathrm{HWE}+1 \mathrm{M} \mathrm{NaOH}$ & 21 & 130 & 2 \\
$\mathrm{HWE}+\mathrm{EtOH} / 0.25 \mathrm{M} \mathrm{NaOH}$ & 22 & 130 & 2
\end{tabular}

General procedure for biomass treatment: mixture of $1.0 \mathrm{~g}$ extractive-free wheat straw or aspen powder after HWE or straight after removal of extractives in a microwave reactor vial with $20 \mathrm{~mL}$ solvent was placed into the reactor with magnetic stirring. After reaction, the solids were separated by vacuum filtration and washed with the compatible solvent to produce fraction $\mathrm{C}$ in Figure 1. Lignin was collected from the liquid fractions (fraction D in Figure 1). Alkaline solutions were acidified, lignin was left to coagulate overnight, and the solids were filtrated. From the formic acid solution, lignin was isolated by concentrating to few milliliters and then adding it drop-wise to $40 \mathrm{~mL}$ of distilled water. In IL procedure, the solutions of $[\mathrm{TEAH}]\left[\mathrm{HSO}_{4}\right]$ were diluted with ethanol before filtration (fraction $\mathrm{C}$ ) to reduce viscosity. The liquids were evaporated to remove volatiles, diluted to $80 \mathrm{~mL}$ with distilled water, and left to coagulate overnight to recover fraction $\mathrm{D}$.

Hemicellulose Carbohydrate Composition. Hemicelluloses in extractive-free wheat straw and aspen and residual hemicelluloses in cellulose fractions $\mathrm{C}$ were analyzed by acid methanolysis. ${ }^{44}$ Details of the analysis method are presented in Supporting Information S1.2. Samples were analyzed with gas chromatography (GC) using Shimadzu GC-2010 (Shimadzu, Japan) GC with HP-1 column $(25 \mathrm{~m}, 0.2 \mathrm{~mm}, 0.11 \mu \mathrm{m})$. Amount of sugars in samples is presented as anhydrosugars.

Lignin Content Analysis. The lignin content was analyzed from fractions $\mathrm{C}$ with the acetyl bromide method, according to Hatfield et al., ${ }^{45}$ detailed procedure in S1.3.

Lignin NMR Characterization. A Bruker AVANCE III $500 \mathrm{MHz}$ FT-NMR-spectrometer with the BBFO broadband probe was used for all experiments. Details of analysis method are given in S1.4. Samples were acetylated and dissolved in $\mathrm{CDCl}_{3}$. Spectra were processed using Bruker TopSpin 3.5pl7.

MWD Analysis. Lignin samples: GPC measurements were performed according to Marinovic et al. ${ }^{46}$ on Waters ACQUITY APC equipment using Acquity APCTM XT $45 \AA$ $(1.7 \mu \mathrm{m}, 4.6 \times 150 \mathrm{~mm})$ and XT $200 \AA(2.5 \mu \mathrm{m}, 4.6 \times 150$ $\mathrm{mm}$ ) columns (Waters Corporation, USA). GPC Empower Software (Waters) was used for data processing to obtain $M_{n}$ (number-average molecular weight), $M_{\mathrm{w}}$ (weight-average molecular weight $)$ and polydispersity PDI $\left(M_{\mathrm{w}} / M_{\mathrm{n}}\right)$. Chromatograms were normalized.

Carbohydrate samples: measurements were performed with Agilent Infinity 1260 LC-system with a refractive index detector from the Agilent 1200 series. Separation was made 
with a precolumn (Agilent PLgel guard $50 \times 7.5 \mathrm{~mm}$ ) and three analytical columns (PLgel Mixed B, $10 \mu \mathrm{m}, 300 \times 7.5$ $\mathrm{mm}$ ). Sample preparation for cellulosic samples was made according to Kakko et al. ${ }^{47}$ Agilent GPC add-on was used for calculations. Weight average degree of polymerization $\left(\mathrm{DP}_{\mathrm{w}}\right)$ of cellulose was calculated by $M_{\mathrm{w}} / \mathrm{AGU}$ (anhydro glucose unit $=162 \mathrm{~g} \mathrm{~mol}^{-1}$ ). Details of analysis methods are given in S1.5.

Ash Content Analysis. Ash contents in wheat straw samples were determined by thermally oxidizing the samples in a muffler oven at $600{ }^{\circ} \mathrm{C}$ and measuring material loss. ${ }^{48}$ Details of the analysis method are given in S1.6.

Pyrolysis-GC-MS Analysis. Pyrolab2000 (Pyrolab, Sweden) analytical-scale equipment directly connected to Bruker Scion SQ456-GC/MS equipped with an Agilent DB5MS UI (5\%-phenyl)-methylpolysiloxane, $30 \mathrm{~m} \times 0.250 \mathrm{~mm} \times$ $0.25 \mu \mathrm{m} \mathrm{l} \mathrm{m)} \mathrm{capillary} \mathrm{column} \mathrm{was} \mathrm{used} \mathrm{for} \mathrm{analysis.} \mathrm{HWE-}$ extracted fractions (A) were analyzed, and carbohydrate versus aromatic fragment ratios were estimated according to Kuuskeri et al. ${ }^{49}$ Details of the analysis method are given in S1.7.

\section{ASSOCIATED CONTENT}

\section{S Supporting Information}

The Supporting Information is available free of charge at https://pubs.acs.org/doi/10.1021/acsomega.9b02619.

Detailed procedures for extractions and analysis, GPC graphs and HSQC-NMR spectra of lignin, cellulose and hemicellulose fractions, selected ${ }^{13} \mathrm{C}$ NMR spectra of lignin samples, and carbohydrate composition analysis results (PDF)

\section{AUTHOR INFORMATION}

\section{Corresponding Author}

*E-mail: paula.nousiainen@helsinki.fi. Phone: +358 2941 50370.

\section{ORCID}

Petri Kilpeläinen: 0000-0002-0982-0123

Kristiina Hildén: 0000-0002-0126-8186

Paula Nousiainen: 0000-0002-7089-1158

Jussi Sipilä: 0000-0002-2957-1443

\section{Author Contributions}

${ }^{\perp}$ U.H. and R.M. contributed equally to this work. The manuscript was written through contributions of all the authors. All the authors have given approval to the final version of the manuscript.

\section{Notes}

The authors declare no competing financial interest.

\section{ACKNOWLEDGMENTS}

For financial support, EU Horizon 2020 (project nr 720918, FALCON) is gratefully acknowledged. J.M. acknowledges support from the Novo Nordisk Foundation grant NNF160C0021704 (LIGNICAT). J.K. acknowledges support from Academy of Finland project no. 298882 (AromaFung). Authors would like to thank Dr. Eila Järvenpää and Pentti Kananen (Natural Resources Institute Finland) for kindly providing harvested wheat straw and aspen sawdust. Dr. SamiPekka Hirvonen is thanked for providing support with the NMR experiments.

\section{REFERENCES}

(1) Shafiee, S.; Topal, E. When will fossil fuel reserves be diminished? Energy Policy 2009, 37, 181-189.

(2) Gutiérrez-Arriaga, C. G.; Serna-González, J. M.; El-Halwagi, M. M.; El-Halwagi, M. M. Sustainable integration of algal biodiesel production with steam electric power plants for greenhouse gas mitigation. ACS Sustainable Chem. Eng. 2014, 2, 1388-1403.

(3) Cherubini, F. The biorefinery concept: Using biomass instead of oil for producing energy and chemicals. Energy Convers. Manage. 2010, $51,1412-1421$.

(4) Hämmerle, F. M. The cellulose gap (The future of cellulose fibres). Lenzinger Ber. 2011, 89, 12-21.

(5) Somerville, C.; Youngs, H.; Taylor, C.; Davis, S. C.; Long, S. P. Feedstocks for lignocellulosic biofuels. Science 2010, 329, 790-792.

(6) Schutyser, W.; Renders, T.; Van den Bosch, S.; Koelewijn, S.-F.; Beckham, G. T.; Sels, B. F. Chemicals from lignin: an interplay of lignocellulose fractionation, depolymerisation, and upgrading. Chem. Soc. Rev. 2018, 47, 852-908.

(7) Wang, H.; Pu, Y.; Ragauskas, A.; Yang, B. From lignin to valuable products-strategies, challenges, and prospects. Bioresour. Technol. 2019, 271, 449-461.

(8) Effendi, A.; Gerhauser, H.; Bridgwater, A. V. Production of renewable phenolic resins by thermochemical conversion of biomass: A review. Renewable Sustainable Energy Rev. 2008, 12, 2092-2116.

(9) Petzold-Welcke, K.; Schwikal, K.; Daus, S.; Heinze, T. Xylan derivatives and their application potential - Mini-review of own results. Carbohydr. Polym. 2014, 100, 80-88.

(10) Sheldon, R. A. Green and sustainable manufacture of chemicals from biomass: state of the art. Green Chem. 2014, 16, 950-963.

(11) Aro, T.; Fatehi, P. Production and application of lignosulfonates and sulfonated lignin. ChemSusChem 2017, 10, 1861-1877.

(12) Deswarte, F. E. I.; Clark, J. H.; Wilson, A. J.; Hardy, J. J. E.; Marriott, R.; Chahal, S. P.; Jackson, C.; Heslop, G.; Birkett, M.; Bruce, T. J.; Whiteley, G. Toward an integrated straw-based biorefinery. Biofuels, Bioprod. Biorefin. 2007, 1, 245-254.

(13) Enqvist, E.; Tikka, P.; Heinrich, L.; Luhtanen, M. Production of pulp using a gaseous organic agent as heating and reactionaccelerating media. U.S. Patent 0,014,138 A1, 2009.

(14) Li, M.-F.; Sun, S.-N.; Xu, F.; Sun, R.-C. Formic acid based organosolv pulping of bamboo (Phyllostachys acuta): Comparative characterization of the dissolved lignins with milled wood lignin. Chem. Eng. J. 2012, 179, 80-89.

(15) Rahimi, A.; Ulbrich, A.; Coon, J. J.; Stahl, S. S. Formic-acidinduced depolymerization of oxidized lignin toaromatics. Nature 2014, 515, 249-252.

(16) da Costa Lopes, A. M.; João, K. G.; Morais, A. R. C.; BogelŁukasik, E.; Bogel-Łukasik, R. Ionic liquids as a tool for lignocellulosic biomass fractionation. Sustainable Chem. Processes 2013, 1, 3.

(17) Wang, H.; Gurau, G.; Rogers, R. D. Ionic liquid processing of cellulose. Chem. Soc. Rev. 2012, 41, 1519-1537.

(18) King, A. W. T.; Asikkala, J.; Mutikainen, I.; Järvi, P.; Kilpeläinen, I. Distillable Acid-Base Conjugate Ionic Liquids for Cellulose Dissolution and Processing. Angew. Chem., Int. Ed. 2011, 50, 6301-6305.

(19) Achinivu, E. C.; Howard, R. M.; Li, G.; Gracz, H.; Henderson, W. A. Lignin extraction from biomass with protic ionic liquids. Green Chem. 2014, 16, 1114-1119.

(20) Brandt-Talbot, A.; Gschwend, F. J. V.; Fennell, P. S.; Lammens, T. M.; Tan, B.; Weale, J.; Hallett, J. P. An economically viable ionic liquid for the fractionation of lignocellulosic biomass. Green Chem. 2017, 19, 3078-3102.

(21) Deb, S.; Labafzadeh, S. R.; Liimatainen, U.; Parviainen, A.; Hauru, L. K. J.; Azhar, S.; Lawoko, M.; Kulomaa, T.; Kakko, T.; Fiskari, J.; Borrega, M.; Sixta, H.; Kilpeläinen, I.; King, A. W. T. Application of mild autohydrolysis to facilitate the dissolution of wood chips in direct-dissolution solvents. Green Chem. 2016, 18, 3286-3294.

(22) Pérez, J. A.; Ballesteros, I.; Ballesteros, M.; Sáez, F.; Negro, M. J.; Manzanares, P. Optimizing liquid hot water pretreatment 
conditions to enhance sugar recovery from wheat straw for fuelethanol production. Fuel 2008, 87, 3640-3647.

(23) Li, M.; Cao, S.; Meng, X.; Studer, M.; Wyman, C. E.; Ragauskas, A. J.; Pu, Y. The effect of liquid hot water pretreatment on the chemical-structural alteration and the reduced recalcitrance in poplar. Biotechnol. Biofuels 2017, 10, 237.

(24) Kilpeläinen, P. O.; Hautala, S. S.; Byman, O. O.; Tanner, L. J.; Korpinen, R. I.; Lillandt, M. K.-J.; Pranovich, A. V.; Kitunen, V. H.; Willför, S. M.; Ilvesniemi, H. S. Pressurized hot water flow-through extraction system scale up from the laboratory to the pilot scale. Green Chem. 2014, 16, 3186-3194.

(25) Mood, S. H.; Golfeshan, A. H.; Tabatabaei, M.; Jouzani, G. S.; Najafi, G. H.; Gholami, M.; Ardjman, M. Lignocellulosic biomass to bioethanol, a comprehensive review with a focus on pretreatment. Renewable Sustainable Energy Rev. 2013, 27, 77-93.

(26) $\mathrm{Hu}, \mathrm{Z}$;; Wen, Z. Enhancing enzymatic digestibility of switchgrass by microwave-assisted alkali pretreatment. Biochem. Eng. J. 2008, 38, 369-378.

(27) Cheng, J.; Su, H.; Zhou, J.; Song, W.; Cen, K. Microwaveassisted alkali pretreatment of rice straw to promote enzymatic hydrolysis and hydrogen production in dark- and photo-fermentation. Int. J. Hydrogen Energy 2011, 36, 2093-2101.

(28) Duarte, G. V.; Ramarao, B. V.; Amidon, T. E.; Ferreira, P. T. Effect of hot water extraction on hardwood kraft pulp fibers (Acer saccharum, Sugar Maple). Ind. Eng. Chem. Res. 2011, 50, 9949-9959.

(29) Amidon, T. E.; Bujanovic, B.; Liu, S.; Howard, J. R. Commercializing biorefinery technology: A case for the multi-product pathway to a viable biorefinery. Forests 2011, 2, 929-947.

(30) Gröndahl, M.; Gatenholm, P. Role of acetyl substitution in hardwood xylan. In Polysaccharides: Structural Diversity and Functional Versatility, 2nd ed.; Dumitriu, S., Ed.; Marcel Dekker: New York, 2004; pp 509-514.

(31) Ebringerová, A.; Heinze, T. Xylan and xylan derivatives biopolymers with valuable properties, 1 . Naturally occurring xylans structures, isolation procedures and properties. Macromol. Rapid Commun. 2000, 21, 542-556.

(32) Farhat, W.; Venditti, R.; Quick, A.; Taha, M.; Mignard, N.; Becquart, F.; Ayoub, A. Hemicellulose extraction and characterization for applications in paper coatings and adhesives. Ind. Crops Prod. 2017, 107, 370-377.

(33) Fang, J. M.; Sun, R. C.; Salisbury, D.; Fowler, P.; Tomkinson, J. Comparative study of hemicelluloses from wheat straw by alkali and hydrogen peroxide extractions. Polym. Degrad. Stab. 1999, 66, 423432.

(34) Penttilä, P. A.; Kilpeläinen, P.; Tolonen, L.; Suuronen, J.-P.; Sixta, H.; Willför, S.; Serimaa, R. Effects of pressurized hot water extraction on the nanoscale structure of birch sawdust. Cellulose 2013, 20, 2335-2347.

(35) Ralph, J.; Landucci, L. L. NMR of lignins. In Lignin and Lignans: Advances in Chemistry, 1st ed.; Heitner, C., Dimmel, D., Schmidt, J., Eds.; CRC Press, 2010; pp 137-244.

(36) Zhao, B.-C.; Chen, B.-Y.; Yang, S.; Yuan, T.-Q.; Charlton, A.; Sun, R.-C. Structural Variation of Lignin and Lignin-Carbohydrate Complex in Eucalyptus grandis $\times$ E. urophylla during Its Growth Process. ACS Sustainable Chem. Eng. 2017, 5, 1113-1122.

(37) Liu, Y.; Chen, W.; Xia, Q.; Guo, B.; Wang, Q.; Liu, S.; Liu, Y.; $\mathrm{Li}, \mathrm{J}$;; Yu, H. Efficient Cleavage of Lignin-Carbohydrate Complexes and Ultrafast Extraction of Lignin Oligomers from Wood Biomass by Microwave-Assisted Treatment with Deep Eutectic Solvent. ChemSusChem 2017, 10, 1692-1700.

(38) Hallac, B. B.; Ragauskas, A. J. Analyzing cellulose degree of polymerization and its relevancy to cellulosic ethanol. Biofuels, Bioprod. Biorefin. 2011, 5, 215-225.

(39) Vishtal, A. G.; Kraslawski, A. Challenges in industrial applications of technical lignins. Bioresearch 2011, 6, 3547-3568.

(40) Zhou, S.; Liu, L.; Wang, B.; Xu, F.; Sun, R. Microwaveenhanced extraction of lignin from birch in formic acid: Structural characterization and antioxidant activity study. Process Biochem. 2012, 47, 1799-1806.
(41) Barana, D.; Salanti, A.; Orlandi, M.; Ali, D. S.; Zoia, L. Biorefinery process for the simultaneous recovery of lignin, hemicelluloses, cellulose nanocrystals and silica from rice husk and Arundo donax. Ind. Crops Prod. 2016, 86, 31-39.

(42) Tang, C.; Chen, Y.; Liu, J.; Shen, T.; Cao, Z.; Shan, J.; Zhu, C.; Ying, H. Sustainable biobutanol production using alkali-catalyzed organosolv pretreated cornstalks. Ind. Crops Prod. 2017, 95, 383-392.

(43) Mihiretu, G. T.; Brodin, M.; Chimphango, A. F.; Øyaas, K.; Hoff, B. H.; Görgens, J. F. Single-step microwave-assisted hot water extraction of hemicelluloses from selected lignocellulosic materials - A biorefinery approach. Bioresour. Technol. 2017, 241, 669-680.

(44) Willför, S.; Pranovich, A.; Tamminen, T.; Puls, J.; Laine, C.; Suurnäkki, A.; Saake, B.; Uotila, K.; Simolin, H.; Hemming, J.; Holmbom, B.; Hemming, J.; Holmblom, B. Carbohydrate analysis of plant materials with uronic acid-containing polysaccharides-A comparison between different hydrolysis and subsequent chromatographic analytical techniques. Ind. Crops Prod. 2009, 29, 571-580.

(45) Hatfield, R. D.; Grabber, J.; Ralph, J.; Brei, K. Using the acetyl bromide assay to determine lignin concentrations in herbaceous plants: Some cautionary notes. J. Agric. Food Chem. 1999, 47, 628632.

(46) Marinović, M.; Nousiainen, P.; Dilokpimol, A.; Kontro, J.; Moore, R.; Sipilä, J.; de Vries, R. P.; Mäkelä, M. R.; Hildén, K. Selective cleavage of lignin $\beta$ - O-4 aryl ether bond by $\beta$-etherase of the white-rot fungus Dichomitus squalens. ACS Sustainable Chem. Eng. 2018, 6, 2878-2882.

(47) Kakko, T.; King, A. W. T.; Kilpeläinen, I. Homogenous esterification of cellulose pulp in [DBNH] [OAc]. Cellulose 2017, 24, 5341-5354.

(48) Hyväkkö, U.; King, A. W. T.; Kilpeläinen, I. Extraction of wheat straw with aqueous tetra- $n$-butylphosphonium hydroxide. Bioresearch 2014, 9, 1565-1577.

(49) Kuuskeri, J.; Häkkinen, M.; Laine, P.; Smolander, O.-P.; Tamene, F.; Miettinen, S.; Nousiainen, P.; Kemell, M.; Auvinen, P.; Lundell, T. Time-scale dynamics of proteome and transcriptome of the white-rot fungus Phlebia radiata: growth on spruce wood and decay effect on lignocellulose. Biotechnol. Biofuels 2016, 9, 192-214. 